\title{
Coletivos: um balanço da literatura sobre as novas formas de mobilização da sociedade civil
}

\author{
Collectives: a balance of literature on the new forms of civil \\ society mobilization
}

Olívia Cristina Perez ${ }^{1}$ e Alberto Luís Araújo Silva Filho²

Resumo: O presente trabalho se insere na subárea da ciência política que abarca os estudos relacionados à sociedade civil e movimentos sociais. No âmbito desse campo de pesquisas, têm sido escassas as análises e investigações que concernem aos chamados coletivos, tidos como formas de mobilização recentes nos espaços acadêmicos e extra-acadêmicos e que se configuram enquanto modalidade de ativismo social multiforme na contemporaneidade. Através desse trabalho, que analisa a maneira pela qual a literatura científica aborda tal objeto de estudo, se pretende preencher essa lacuna identificada em investigação realizada no interior das mais diversas

\footnotetext{
${ }^{1}$ Doutora em Ciência Política pela USP mestre em Sociologia também pela USP e especialista em Tecnologias, Formação de Professores e Sociedade pela UNIFEI. Cursou o bacharelado e licenciatura plena em Ciências Sociais na UNESP. Atualmente é Professora Adjunta no curso de Ciência Política da Universidade Federal do Piauí (UFPI). Email: oliviacperez@yahoo.com.br

2 Graduando em Ciência Política pela Universidade Federal do Piauí, membro do Grupo de Pesquisas sobre Instituições e Políticas Públicas (CNPq), na linha de investigações sobre teoria política contemporânea e membro associado da ALACIP Jovem, na linha de pesquisas sobre movimentos sociais no contexto latino-americano. E-mail: albertosilvaterra@hotmail.com
}

Latitude, Vol. 11, no 1 , pp. 255-294, 2017

DOI: https://doi.org/10.28998/2179-5428.20170107 


\title{
Coletivos: um balanço da literatura sobre as novas formas de mobilização da sociedade civil
}

plataformas de artigos acadêmicos. Para isso, se utilizará tanto da seleção criteriosa de estudos de caso sobre coletivos quanto da discussão teórico-conceitual acerca dessas novas formas de mobilização. Os resultados apontam para a ausência de análises teóricas que definam o que sejam os coletivos mas aqui é feita uma primeira definição do objeto de pesquisa. Dessa forma, a inclusão do presente estudo na literatura da subárea contribui para a compreensão e sistematização bibliográfica da maneira pela qual os autores têm lidado com esse fenômeno.

Palavras-chave: Coletivos; Movimentos Sociais; Sociedade Civil.

\begin{abstract}
The present work falls within the subarea of political science that encompasses studies related to civil society and social movements. Within this field of research, there have been few analyses and investigations concerning the so-called collectives, which have been seen as recent forms of mobilization in academic and extraacademic spaces, and which constitute a form of multi-social social activism in contemporary times. Through this work, which analyzes by means of clippings the way in which the scientific literature addresses this object of study, it is intended to fill this gap identified in research carried out within the most diverse platforms of academic articles. We will use both the careful selection of case studies on collectives and the theoretical-conceptual discussion about these new forms of mobilization. The results point to the absence of theoretical analyzes that define what the collectives are but here is presented a first definition of the research object. Thus, the inclusion of the present study in the literature of the subarea contributes to the understanding and bibliographical systematization of the way in which the authors have dealt with this phenomenon.
\end{abstract}

Keywords: Collectives; Social Movements; Civil Society.

\section{Introdução}




\section{Olívia Cristina Perez e Alberto Luís Araújo Silva Filho}

Novas formas de mobilização da sociedade civil conhecidas como coletivos vem pautando discussões sobre gênero, raça, orientação sexual e outros marcadores sociais das diferenças, especialmente nas universidades e redes sociais.

$\mathrm{Na}$ cidade de Teresina (capital do estado do Piauí) coletivos como o Batuque Feminista, Kátias Coletivas, Grupo Matizes e Liga LGBT promovem debates relacionados à questão de gênero e identidade LGBT. Existe um auto reconhecimento enquanto coletivo por essas organizações que que têm origem recente e ligada à Universidade - local onde se encontram e desenvolvem suas atividades. Inclusive, o contato com os sujeitos ali inseridos se dá majoritariamente por meio de eventos promovidos no interior da academia e divulgados pelo meio virtual. Aliás a atuação em redes sociais virtuais é uma marca desses coletivos, que promovem debates também no meio virtual. Em geral as discussões têm como objetivo o empoderamento de sujeitos oprimidos por conta das clivagens sociais. Portanto, trata-se de um ativismo com forte presença no meio universitário que acompanha, reforça e é alimentado pelo debate acadêmico.

Com base na análise dos estudos teórico-empíricos acerca dos coletivos, modalidades de engajamento que se inserem no quadro mais recente da abordagem acerca dos movimentos sociais, nesse artigo, busca-se investigar como os mesmos, considerados como novas formas de mobilização da sociedade civil têm sido analisadas no âmbito da literatura sobre os novos movimentos sociais e subáreas afins.

Especificamente foram feitas buscas em artigos científicos que tratam do fenômeno e seus resultados foram sistematizados utilizando a técnica de revisão sistemática da literatura. A revisão sistemática é uma forma de pesquisa que parte de fonte de dados disponíveis na literatura, mediante a aplicação de critérios específicos. Tal técnica é útil para integrar 
Coletivos: um balanço da literatura sobre as novas formas de mobilização da sociedade civil

as informações de um conjunto de estudos realizados separadamente. (SAMPAIO e MANCINI, 2007). Logo, trata-se de uma pesquisa bibliográfica que organiza os resultados derivados de outras pesquisas. Essa é uma técnica qualitativa na medida em que analisa com profundidade os resultados alcançados, revelando seus aspectos implícitos.

Com isso, objetiva-se a reunião de referenciais de estudo que possam esclarecer como essas mobilizações surgem, se estruturam e em quais temáticas mais tem atuado nos últimos anos, contribuindo enquanto ponto de partida para futuras pesquisas empíricas que tenham como foco essa modalidade de luta ainda escassamente explorada.

O trabalho está dividido em três partes. Primeiramente são apresentados traços centrais da contemporaneidade que estimulam a formação dos chamados novos movimentos sociais pautados pela luta pelo reconhecimento de identidades. Em seguida são detalhados os procedimentos metodológicos seguidos na pesquisa. Na terceira seção encontram-se os resultados da investigação, mais especificamente a sistematização de artigos que tem os coletivos como objetos de estudos, bem como análises sobre os mesmos de onde desprende-se uma definição de coletivos apresentada na conclusão da pesquisa.

\section{Movimentos sociais}

Para as teorias que historicamente tentaram compreender os movimentos sociais, o final da década de 1960 foi demarcado enquanto ponto de inflexão "paradigmático", na medida em que o tradicional quadro explicativo, conhecido pela denominação de modelo clássico, não conseguia mais abranger os novos processos de subjetivação que emergiam. Esses incluíam mobilizações em prol dos direitos das mulheres por todo o Ocidente, dos direitos civis para os negros na 


\section{Olívia Cristina Perez e Alberto Luís Araújo Silva Filho}

sociedade norte-americana, do fim da guerra do Vietnã, entre outros que buscavam a afirmação das identidades, o reconhecimento de novos estilos de vida e a visibilidade de múltiplas formas de enquadramento social, que incluiriam entre seus pressupostos a paz e a afetividade (ALONSO, 2009).

Logo, a teorização que antes esteve baseada no marxismo e sua ênfase lógica em torno das relações de produção passou a orbitar em torno de outros panoramas que dessem conta de esclarecer os aspectos dos "modernos" conflitos que começavam a ser colocados no centro do debate. Porém, é importante pontuar que mesmo com a modificação do eixo explicativo, os aspectos materiais não saíram de cena por completo, fazendo com que a teoria dos novos movimentos sociais, elaborada inicialmente através da crítica do sociólogo francês Alain Touraine ao materialismo, ocupasse o papel simbólico de atualizadora da vertente teórica clássica já instituída (ALEXANDER, 1998).

Os ditames dessa teoria apontavam para a urgência em enxergar os movimentos sob outro prisma, já que protestos como os ocorridos em 1968 mostraram que não eram apenas as condições de exploração pelo trabalho que ocasionavam a opressão dos sujeitos, mas também a supressão das individualidades advinda do modelo sociocultural vigente (ALONSO, 2009).

Dessa maneira, a contestação aos padrões culturais passou a fundamentar boa parte das manifestações do Ocidente no contexto de transição para uma sociedade "programada" ou "pós-industrial" (TOURAINE, 1983). Nesse novo estágio, o conflito é deslocado para outras arenas, que não apenas a econômica, demonstrando que a contraposição à ordem se dá onde essa se encontra invariavelmente instituída, e que os movimentos sociais não são meros agregadores de preferências, mas também formadores de laços de solidariedade e identidade (MELUCCI, 1989). 
Coletivos: um balanço da literatura sobre as novas formas de mobilização da sociedade civil

Esse novo caminho teria sido traçado não só porque ficaram explicitadas as novas formas de dominação, para além da econômica, mas também porque o próprio encaminhamento contínuo de demandas em direção ao Estado no período que ficou conhecido como a "era de ouro" do capitalismo (HOBSBAWN, 1995) gerou uma hipertrofia regulatória que teve como um dos resultados a tentativa de racionalizar jurídica e administrativamente a vida privada, colonizando o chamado "mundo da vida", no qual se dão os fluxos interativos interpessoais (HABERMAS, 1981).

Os novos movimentos sociais, que na passagem dos anos 1960 para os anos 1970 passaram a ser evidenciados através de algumas batalhas identitárias, foram evoluindo com o decorrer do tempo. Na década de 1980, mesmo no Brasil, era evidente o aparecimento de organizações da juventude, dos ambientalistas e de sujeitos engajados na luta pelas reformas agrária e urbana (GOHN, 2011).

No plano externo, o avanço da globalização e dos ajustes estruturais de caráter neoliberal, na década de 1990, deu impulso à formação de movimentos altermundialistas que questionavam o caráter excludente dos novos receituários impostos. Da manifestação de Seattle em 1999, passando pelos zapatistas e chegando até o Fórum Social Mundial, essas novas mobilizações tinham como pressuposto expor as contradições de toda ordem provenientes do avanço da economia de mercado em livre processo de desregulamentação (PEREIRA, 2013). Os assim autointitulados coletivos são um fenômeno que emerge no contexto das mobilizações de contestação ao neoliberalismo e de afirmação das diferenças culturais e das identidades.

Em linhas gerais, duas correntes de análises contemporâneas se concentram na explicação sobre $\mathrm{O}$ surgimento e desenvolvimento dos movimentos sociais: a teoria do confronto político e a teoria dos novos movimentos sociais. 


\section{Olívia Cristina Perez e Alberto Luís Araújo Silva Filho}

A primeira destaca o confronto como uma das principais características dos movimentos sociais. Conforme Sidney Tarrow (2009), os movimentos sociais são compreendidos como "desafios coletivos baseados em objetivos comuns e solidariedade social numa interação sustentada com as elites, opositores e autoridade" (TARROW, 2009, p. 21), logo, o autor destaca a interação entre atores e instituições, mas também a posição conflituosa subjacente à própria definição de opositores e autoridades.

Embora trata-se de uma política contenciosa, a interação entre grupos reivindicantes, aliados e autoridades também é destacada por autores dessa corrente, construindo assim uma perspectiva relacional (TILLY, 2009). Aliás, a compreensão das múltiplas formas de intersecção entre movimentos sociais e o Estado, tais como a presença de movimentos sociais dentro do aparato estatal, assim como as redes que cruzam as fronteiras entre Estado e sociedade civil, são hoje um importante caminho analítico de estudos sobre movimentos sociais (ABERS e VON BÜLOW, 2011; LAVALLE e SWAKO, 2015).

Outra corrente de análise chamada de teoria dos novos movimentos sociais se concentra nas características das sociedades contemporâneos que levam a novas formas de mobilização social com atuação pacífica e organizações fluidas não hierárquica e desburocratizadas. Os movimentos sociais como categoria analítica seriam uma forma de ação coletiva baseada na solidariedade e na reafirmação de demandas simbólicas (MELUCCI, 1989).

\section{Metodologia}

Essa é uma pesquisa qualitativa na medida em que analisa com profundidade os objetos de estudos, quais sejam: a concepção sobre coletivos presentes nos artigos científicos públicos sore o tema. 
Coletivos: um balanço da literatura sobre as novas formas de mobilização da sociedade civil

A técnica empregada na pesquisa é denominada revisão sistemática da literatura, comum principalmente na área das ciências da saúde. Trata-se da seleção criteriosa de trabalhos com vistas a reunir um conhecimento sobre determinado assunto. As revisões sistemáticas são úteis para integrar as informações de um conjunto de estudos realizados separadamente, bem como identificar temas que necessitam de evidência, auxiliando na orientação para investigações futuras. (SAMPAIO e MANCINI, 2007, p.84).

Para a pesquisa foram investigados A artigos e textos acadêmicos nos quais pudesse ser detectada a menção aos coletivos, seja explorando a literatura nacional quanto a estrangeira.

A busca se deu por meio de plataformas acadêmicas online, dentre as quais a Scielo, dentre outras que se encontram disponíveis internamente a Periódicos CAPES. Na divisão de plataformas que será listada em tabela mais abaixo, a Periódico CAPES é distinguida de plataformas internas a ela, pois apesar das mesmas estarem disponíveis em seu site, a Periódico CAPES impõe determinadas restrições ao acesso, enquanto a Scielo e outras são abertas ao público.

No âmbito da pesquisa, foram utilizados os termos "coletivos", "colectivos", "collectives" e collectives". Foi encontrado um total de vinte artigos que utilizam a palavra "coletivo" no sentido de agregação de pessoas. Após a localização desses artigos foi feita uma análise para que fossem abarcados aqueles que se referiam aos objetos de estudo, coletivos como formas de mobilização a sociedade civil. Passada essa triagem inicial foram selecionados doze trabalhos.

Todos os trabalhos foram submetidos a uma revisão sistemática da literatura, ou seja, foram lidos e sintetizados com vistas a responder o problema de pesquisa: o que são os coletivos segundo os artigos científicos que abordam o tema? 
Olívia Cristina Perez e Alberto Luís Araújo Silva Filho

\section{Resultados}

Os textos foram divididos em três grandes grupos: os da literatura latino-americana ou de língua espanhola (textos do Chile e Venezuela), os da literatura em língua inglesa que incluem produções dos EUA e da Índia, além dos textos da literatura nacional, que estão separados por subtemas trabalhados pelos coletivos. Também foram destacados o ano da publicação, presença de definição do fenômeno no artigo, além das plataformas nas quais os mesmos foram encontrados. Seguem resultados no quadro 1. 
Quadro 1- Sistematização da literatura sobre coletivos

\begin{tabular}{|c|c|c|c|c|}
\hline Nome do artigo/Indicação de autoria & $\begin{array}{c}\text { Plataforma de } \\
\text { origem }\end{array}$ & $\begin{array}{l}\text { País de } \\
\text { origem }\end{array}$ & $\begin{array}{c}\text { Tema } \\
\text { abordado }\end{array}$ & $\begin{array}{l}\text { Presença de definição do fenômeno? } \\
\text { Qual? }\end{array}$ \\
\hline $\begin{array}{l}\text { 1. A juventude e os coletivos: como se } \\
\text { articulam novas formas de expressão política } \\
\text { (MAIA, 2013) }\end{array}$ & $\begin{array}{l}\text { Periódicos } \\
\text { UFSM }\end{array}$ & Brasil & Representação & $\begin{array}{l}\text { Sim. Formas de mobilização baseadas na } \\
\text { multiplicidade e na temporalidade das pautas. }\end{array}$ \\
\hline $\begin{array}{l}\text { 2. Cultura e política: a experiência dos coletivos } \\
\text { de cultura no movimento estudantil } \\
\text { (MESQUITA, 2008) }\end{array}$ & $\begin{array}{l}\text { Periódicos } \\
\text { CAPES }\end{array}$ & Brasil & Arte e cultura & Não \\
\hline 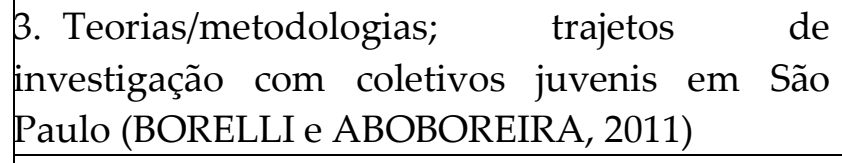 & $\begin{array}{l}\text { Periódicos } \\
\text { CAPES }\end{array}$ & Brasil & Arte e cultura & Não \\
\hline $\begin{array}{l}\text { 4. O Coletivo (com preguiça): encontros, fluxos, } \\
\text { pausas, artes (AMADOR e CASTRO, 2016) }\end{array}$ & Scielo & Brasil & Arte e cultura & $\begin{array}{l}\text { Sim. Formas de mobilização na circunscrição de } \\
\text { afetos e na fluidez. }\end{array}$ \\
\hline $\begin{array}{l}\text { 5. Coletivo da música: um estudo sobre } \\
\text { relações entre arte e saúde mental (SIQUEIRA e } \\
\text { LAGO, 2012) }\end{array}$ & Academia.Edu & Brasil & Música & Não \\
\hline
\end{tabular}




\begin{tabular}{|l|l|l|l|l|}
\hline $\begin{array}{l}\text { 6. Participação social e protagonismo em saúde } \\
\text { mental: a insurgência de um coletivo (COSTA e } \\
\text { PAULON, 2012) }\end{array}$ & Scielo & Brasil & Representação & $\begin{array}{l}\text { Sim. Associação entre diferentes sujeitos em } \\
\text { oposição ao indivíduo ou individual. }\end{array}$ \\
\hline $\begin{array}{l}\text { 7. Margeando ativismos globalizados: nas } \\
\text { bordas do Mujeres Al Borde (FERREIRA, 2015) }\end{array}$ & Scielo & Brasil & $\begin{array}{l}\text { Gênero e } \\
\text { sexualidade }\end{array}$ & Não \\
\hline $\begin{array}{l}\text { 8. “Nos habíamos amado tanto". } \\
\text { Añosrevueltos. Mujeres, colectivos y lapelea por } \\
\text { elespacio público (SAPRIEZA, 2015) }\end{array}$ & & Uruguai & Gênero & Não \\
\hline $\begin{array}{l}\text { 9. De Política de Representación a Política de } \\
\text { Coalición? Posibilidades de Movilización } \\
\text { Feminista em el Chile Post-Dictadura(MORA e } \\
\text { RIOS, 2009) }\end{array}$ & Scielo & Venezuela & Gênero & Não \\
\hline $\begin{array}{l}\text { 10.How alternative ideas become institutions: } \\
\text { the case of feminist collectives (BORDT, 1990) }\end{array}$ & Sage PUB & EUA & Gênero & $\begin{array}{l}\text { Sim. Formas de mobilização pautadas pela } \\
\text { horizontalidade, não institucionalidade, divisão do } \\
\text { trabalho, rotatividade da liderança, distribuição } \\
\text { igual de informações e predominância de ideias } \\
\text { comunitárias, holísticas e pessoais. }\end{array}$ \\
\hline
\end{tabular}


Coletivos: um balanço da literatura sobre as novas formas de mobilização da sociedade civil

\begin{tabular}{|l|l|l|l|l|}
\hline $\begin{array}{l}\text { 11.The Strenght of Collective Processes: An } \\
\text { "Outcome Analysis" of Women's Collectives in } \\
\text { India (DESOUZA, 2012) }\end{array}$ & Índia & Gênero & Não \\
\hline $\begin{array}{l}\text { 12.Living a Feminist Lifestyle: The Intersection } \\
\text { of Theory and Action in a Lesbian Feminist } \\
\text { Collective (VALK, 2002) }\end{array}$ & & EUA & $\begin{array}{l}\text { Gênero e Não } \\
\text { sexualidade }\end{array}$ & Não \\
\hline
\end{tabular}


Percebe-se primeiramente o baixo número de artigos sobre o tema - apenas doze. Uma das hipóteses que podem explicar essa ausência de estudos é o fato de que só recentemente os coletivos têm se formado nos espaços acadêmicos e nas mais variadas arenas não institucionais, exigindo um olhar mais apurado dos pesquisadores que já lidam com literaturas sobre formas de mobilização mais antigas.

Outro dado que chama a atenção é a recorrência da temática de gênero, que pode ser explicada pelo fato de que nos últimos anos tem emergido uma série de discussões acerca de questões denominadas pós-materiais dentro dos espaços universitários e fora deles.

A comparação entre o que representam os "coletivos" nos estudos observados em relação ao que a teoria tem apontado como característica das modalidades que se contrapõem aos movimentos sociais tradicionais indica importantes similaridades a serem exploradas não só nessa, mas também em análises posteriores. Segundo Rebecca L.Bordt, estudiosa de gênero da Universidade Depauw nos Estados Unidos, os coletivos possuem os seguintes aspectos:

(...) (a) a autoridade não é uma, mas distribuída entre todos os membros; (b) a liderança é rotativa e temporária, facilitando o ingresso de cada um dos sujeitos integrantes nesse posto; (c) a tomada das decisões é essencialmente participativa; (d) a divisão do trabalho é mínima; (e) informações, recursos e recompensas são distribuídos igualmente; (f) o poder é visto mais como uma forma de emponderamento do que de dominação; (g) os processos de organização são tão valiosos quanto os resultados; (h) as relações sociais são 
Coletivos: um balanço da literatura sobre as novas formas de mobilização da sociedade civil

baseadas em ideias pessoais, comunitárias e holísticas (BORDT, 1990, p.134).

Todas essas peculiaridades se somam, no caso analisado pela pesquisadora, com o fato de que os coletivos feministas estudados pela mesma são compostos apenas por mulheres, ou seja, os agentes porta-vozes das reivindicações são os mesmos agentes que as demandam. Nessa concepção do que sejam os coletivos apresentada por Rebecca L.Bordt, as formas de organização que incluem a horizontalidade e a rotatividade entre seus princípios basilares estão incluídas no grupo "coletivista", no sentido de reunião do coletivo, em oposição às formas "institucionalistas".

Logo, os coletivos não possuem formas institucionalizadas tais quais as de um sindicato, de um partido político ou mesmo de alguns movimentos sociais tradicionais, que com o desenvolvimento do processo histórico foram incorporando cada vez mais dispositivos formais à sua estrutura.

Institucionalização ou não institucionalização variam muito conforme a situação na qual se encontra a forma de mobilização da sociedade civil que queira se analisar. Portanto, não são categorias absolutas como já ficou claro na teoria neoinstitucionalista nos anos 1980, corrente hegemônica na ciência política (RIBEIRO, 2012). Há uma linha que vai desde a completa ausência de resquícios de institucionalidade e uma fase final na qual a estrutura já é totalmente institucional (BORDT, 1990).

No caso dos coletivos, eles podem ser mais ou menos institucionalizados. Isso vai depender muito da gênese e do processo organizativo no qual estão baseados. Os coletivos aos quais Bordt analisa, apesar de possuírem um ambiente próprio e não exatamente estarem ligados a formas fixas e rígidas, dependem em algum nível de dispositivos que tem o seu lugar 
no Estado. Por exemplo, a justiça criminal e programas de atendimento para a saúde, em caso de violência contra a mulher (BORDT, 1990).

Como aborda a autora, parte considerável dos coletivos feministas foi surgindo na sociedade norte-americana no bojo da "nova esquerda", ao final dos anos 1960. A ideia na época de trazer à tona demandas de reconhecimento foi se firmando através de diferentes meios, nos quais se incluíram mobilizações de rua, atos simbólicos e até mesmo publicações "panfletárias" que divergiam entre si (VALK, 2002).

Algumas afirmavam a necessidade de produzir teoria em prol de uma ação política esclarecida e outras reiteravam a precisão por uma linguagem clara que alcançasse o maior número de mulheres possível (VALK, 2002). A descrição do trabalho desses coletivos já nas décadas de 1960 e 1970 realizada por Anne M. Valk dialoga com o levantamento feito na medida em que expressa a histórica multiplicidade de temáticas e abordagens desses novos movimentos sociais: os chamados "coletivos".

Pensar a caracterização dos coletivos é não só pensar os princípios que os regem e as suas múltiplas possibilidades de abordagem, mas também os fins aos quais se propõem. Os movimentos sociais tradicionais que foram ganhando protagonismo a partir da aceleração da Revolução Industrial no século XIX agiam intencionalmente visando a conquista de direitos para a classe trabalhadora, espoliada economicamente no processo produtivo capitalista.

Já os novos movimentos sociais desde que foram aparecendo vão na direção estratégica de combate aos modelos sociais burgueses. Cabe a pergunta: os coletivos, enquanto novas formas de mobilização da sociedade civil, também seguem esse caminho? Isso irá variar conforme a pauta a que o coletivo se propõe. Demandas de reconhecimento estão mais propensas a aproximá-lo de tal categorização. É importante 
Coletivos: um balanço da literatura sobre as novas formas de mobilização da sociedade civil

ressaltar que o paralelismo com esse "tipo ideal" de novo movimento social também se faz considerando que por sê-lo não necessariamente reivindicações materiais estão excluídas, apesar de estarem em um grupo predominado por reivindicações simbólicas (ALONSO, 2009).

$\mathrm{Na}$ busca realizada seis coletivos discutem questões relacionadas à gênero, enquanto três atuam na área de arte e cultura, somente um com música e o outro com representação. Logo, existe uma luta identitária assim como apontado pelos teóricos dos novos movimentos sociais (TOURAINE, 1983; MELUCCI, 1989).

Mesmo no caso dos coletivos de saúde buscados durante o estudo, pode-se falar de um modelo afirmativo e logo de um confronto com as estruturas morais tradicionais (COSTA, PAULON, 2012).

Outra aproximação conceitual levantada é a que está presente em estudo realizado pela jurista Gretha Leite Maia (2013) da UFC em dois coletivos presentes na Universidade Federal do Ceará.

Com base na entrevista de um dos sujeitos que integra um dos coletivos analisados, o Coletivo Conteste criado na Faculdade de Direito da UFC, essas formas de mobilização diferem dos movimentos sociais tradicionais devido ao grande número de pautas possível e à sua efemeridade (MAIA, 2013). O dilema aqui é o de que só é ressaltado um aspecto possível, sendo uma aproximação conceitual marcada pela incompletude. Essa característica pode ser somada, porém, com as apontadas no conceito de Bordt, tendo em vista abarcar os variados tipos de coletivos.

Tendo em vista as características apontadas tanto por Bordt(1990) quanto pelos dois autores nacionais, é possível definir os coletivos enquanto formas de mobilização da sociedade civil regidas pelos princípios da horizontalidade, não institucionalidade, temporalidade e auto-organização. Por auto- 
organização entende-se, não como está pressuposto em uma definição filosófica ou das ciências naturais, o desenvolvimento e a estruturação dos movimentos a partir única e exclusivamente dos seus sujeitos integrantes, sem a imposição de ligações por elementos alheios ao coletivo.

Por sua vez, a temporalidade indica que os coletivos podem ou não adquirir um caráter permanente, tendo a sua vigência restrita a algum momento específico no qual as pautas abordadas são mais propensas ao atendimento por parte de outros atores sociais ou nos quais os sujeitos integrantes estão mais bem alinhados ao redor da organização. Dessa forma, os coletivos são dentre os novos movimentos sociais aqueles que se encontram marcados pela fluidez.

É possível detectar a existência de coletivos de arte e cultura, de gênero, de raça, de orientação sexual, de saúde etc. Cada um desses difere na temática, mas compartilha de um ou outro ponto mais geral. Assim como a institucionalidade não é absoluta, também não o é o enquadramento de uma mobilização enquanto coletivo. Podem surgir, dependendo do caso que está sendo analisado, menores ou maiores índices de "coletivismo" (BORDT, 1990).

Quando se fala em mensuração, não é do caráter quantitativo que se está tratando, mas de parâmetros aproximativos subjetivos. A ressalva é quanto ao afastamento de tentativas de "aritimetização" do debate, mas nem mesmo a qualificação dessas mobilizações faz parte do objeto de análise. A pluralidade dos coletivos e a ausência de regulamentos que os guiem afastam o estudo dessa tarefa.

Quando analisados o país e regiões nos quais os textos foram publicados é possível perceber diferenças nas definições: o termo "coletivo" nos textos latino-americanos possui sentido de agrupamento e não de movimento social. Logo, coletivo feminista é muitas vezes entendido meramente como a própria junção de mulheres em prol da reivindicação por seus direitos; 
Coletivos: um balanço da literatura sobre as novas formas de mobilização da sociedade civil

na literatura em língua inglesa, foi possível constatar a presença de estudos que compreendem os coletivos no sentido dos objetos de estudo aqui analisados e também algumas análises em regiões do Sul Global; já no Brasil são escassos estudos sobre esse tipo de mobilização social, o que torna difícil encontrar aspectos conceituais, que não parecem ser preocupação dos que estão analisando os coletivos, e o que justifica até mesmo a definição proposta nesse artigo como ponto de partida.

A investigação sobre coletivos na América Latina está pautada especificamente na pesquisa sobre coletivos de mulheres, predominantemente encontrados quando da análise mais detida e base para o entendimento de inúmeros coletivos atuais de afirmação e reconhecimento.

Tendo isso em mãos, parte-se do princípio de que devem ser compreendidas as origens do movimento feminista e o seu avanço em alguns países da região, tendo em vista a localização do próprio Brasil nos contextos políticos abarcados pelos estudos regionais. É claro que não se pode esquecer que o entendimento dos autores nesse grupo está contraposto à definição dada, já que os coletivos são compreendidos não como movimentos sociais, mas em seu significado literal de "agrupamento". Dois países serão aqui ressaltados como amostra do contexto latino-americano mais geral: Chile e Uruguai.

No artigo Noshabíamos amado tanto. Añosrevueltos. Mujeres, colectivos y lapelea por elespaciopublico, a professora Graciela Sapriza da Universidade da República no Uruguai expõe dentro do texto a maneira pela qual se deu o desenvolvimento do feminismo uruguaio, desde a conquista do direito ao voto até os governos da Frente Ampla (esquerda) nos anos 2010.

Inicialmente, o alcance ao direito do voto era visto, assim como em outros países, como a grande e última conquista 
das mulheres (SAPRIZA, 2015). O acontecimento suscitava entre a sociedade uruguaia dos anos 1930 e 1940 o seguinte questionamento: "se as mulheres conquistaram o direito ao voto, o que mais podem querer?" (SAPRIZA, 2015). De fato, o Uruguai foi uma das nações da região que mais rápido conseguiu proporcionar a igualdade de direitos entre homens e mulheres, criando um mito da perfeita igualdade entre ambos os sexos (SAPRIZA, 2015).

A questão é que esse imaginário, quando reforçado, acabou por gerar naquele país um estado de anomia e enfraquecimento do movimento feminista, tendo em vista o estereótipo da "inutilidade" que o mesmo representava. Tanto que setores sufragistas que antes reivindicavam o direito ao voto e comemoraram quando da sua conquista, passaram a vêlo como fator propulsor de uma ampla derrocada na emissão das pautas, já que o próprio discurso da igualdade passou a ser usado pelos políticos conservadores.

No entanto, não foi só pela apropriação de dilemas do movimento feminista uruguaio, essencialmente sufragista, que ficou marcada a década de 1940. Com as leis igualitárias aprovadas como a Lei dos Direitos Civis, as primeiras mulheres passaram a ingressar na política, processo que se aceleraria vinte anos mais tarde.

Na década de 1960, o avanço dos movimentos sociais no país, influenciado pela onda de mobilizações que ocorre em todo o Ocidente, faz com que a participação política passe a ser vislumbrada como um horizonte pelas mulheres (SAPRIZA, 2015). Uma série de modificações no paradigma cultural proporcionou o ingresso de sujeitos do sexo feminino em movimentos e partidos políticos de esquerda, sindicatos, guerrilhas urbanas etc. dando às mulheres um "papel protagonista de primeira linha" (SAPRIZA, 2015, p.943). Entretanto, uma nova onda viria a mudar o curso dos avanços 
Coletivos: um balanço da literatura sobre as novas formas de mobilização da sociedade civil

femininos no Uruguai: o período de golpes militares que se sucederam à onda de democratização anterior.

Às mulheres as quais nas experiências democráticas estiveram reservados lugares centrais na vida pública, passam a voltar de certa forma para espaços secundarizados tal qual anteriormente. Além do aspecto cultural patriarcal arraigado ao conservadorismo dos governos militares, também o momento de repressão gerou determinadas demandas atendidas pela via de atividades "tipicamente femininas" (SAPRIZA, 2015, p. 943).

Quais eram essas? No âmbito social, a presença em organizações de direitos humanos para prestação de atendimento às vitimas diretas do regime ditatorial; no âmbito privado, a luta pela manutenção e a adaptação familiar em um contexto de novas circunstâncias. As discussões políticas que antes moviam certo número de mulheres acabaram sendo deixadas de lado no debate, o que se deve ao próprio arrefecimento do movimento feminista que temia a repressão dos aparelhos estatais.

Com a gradual deslegitimação do governo então instituído, dada a evidente opressão gerada pelo terrorismo de Estado e a deterioração das condições de vida, a campanha em prol da redemocratização passou a ser a "agenda do dia" da sociedade uruguaia a partir dos anos 80, paralelamente aos processos de esgotamento dos regimes militares em outros países da América Latina.

Com isso, as mulheres voltam à cena pública, não só engajadas nessa luta de "redemocratização", mas também na de devolução à democracia que estava por vir do seu verdadeiro significado, qual seja, o da ampla participação de todos os segmentos. A intenção era atender as reivindicações participativas das mulheres, na medida em que a ditadura não havia permitido a sua plena expressão.

O grande problema é que mesmo com o fato de que as mulheres estivessem ocupando papel de relevância nos 
movimentos sociais que estavam emergindo, a sua participação efetiva no Parlamento, pelo menos nas primeiras eleições pósredemocratização, continuou nula. Várias correntes se consolidaram, mas a materialização da presença política teve de ser basicamente adiada (SAPRIZA, 2015).

Na segunda metade da década de 1980, o protagonismo feminino fica evidente com a presença de três mulheres na presidência da Comissão do Referendo que viria a decidir ou não pela derrubada da versão uruguaia do que ficou conhecido no Brasil como a "Lei da Anistia", já que a impunidade de pessoas responsáveis pela morte e tortura de inúmeros opositores acabou gerando uma ampla mobilização por parte de parentes das vítimas (SAPRIZA, 2015).

A temática da "igualdade de gênero" começa a entrar na agenda pública dos países latino-americano e em um conjunto enorme de nações pelo mundo a partir da década de 1980. Isso ocorre em função do desenvolvimento da adoção por parte da ONU do lema dos direitos equânimes entre homens e mulheres. Falar do ser "mulher" já era tema discutido na organização desde os anos 1970, tendo em vista a realização da Conferência Intergovernamental no ano de 1975 que estabelecia o Ano Internacional da Mulher (SAPRIZA, 2015).

Pode-se observar nas organizações e encontros periódicos de mulheres que eram constituídos na época determinados traços dos chamados coletivos. Graciela Sapriza não invoca o termo em nenhum momento, mas afirma claramente que esses movimentos preferiram adotar uma "ação autônoma" frente à institucionalidade estatal e internacional (SAPRIZA, 2015, p.248), o que não retira o fato de que aquelas que estiveram nas mobilizações faziam intercâmbio constante com o Estado, reproduzindo o dilema de coletivos feministas norte-americanos (BORDT, 1990) e de alguns coletivos de cultura da cidade de São Paulo que possuem ligação com a 
Coletivos: um balanço da literatura sobre as novas formas de mobilização da sociedade civil

Secretaria de Cultura do Estado (BORELLI, ABOBOREIRA, 2011).

Logicamente que a afirmação de que esses movimentos possuíram alguns traços do que se está chamando modernamente de coletivos, não significa que o sejam. A afirmação se faz para efeito de comparação, pois assemelhá-los a organizações puramente horizontais e afastadas da institucionalidade não possui respaldo empírico. A maior parte do movimento feminista uruguaio optou por na década de 1990 influir em políticas específicas do Estado, mesma direção tomada pelos movimentos sociais brasileiros autônomos no período pós-1988 (AVRITZER, 2012).

Com conquistas interna e externamente, passam então a serem monitoradas as políticas públicas para as mulheres nos países do Sul Global, chegando-se a instalar uma Comissão de Segmentos, responsável por definir objetivos e prioridades no que diz respeito à questão feminina (SAPRIZA, 2015). Nos anos 2000, outros temas passam a ocupar lugar no debate público realizado.

Esse deslocamento parcial de eixo reflete a transição mesma dos governos neoliberais da década de 1990 para as experiências de esquerda e centro esquerda na América Latina. Com isso, a possibilidade de discutir temas de reconhecimento se amplia, já que os partidos de esquerda estão mais propensos a gerar determinadas "janelas de oportunidades" (TILLY, 2000) quando se encontram no poder, o que não quer dizer que todas as demandas dos grupos demandantes serão atendidas.

Em 2002, o tema da saúde sexual e reprodutiva da mulher ganha espaço no Uruguai quando da instauração da votação sobre a lei de despenalização do aborto, que é aprovada na Câmara dos Representantes e rejeitada no Senado. Mesmo com a derrubada da pauta naquele ano, um imenso número de organizações feministas e de redes de mulheres se articularam 
em torno do confronto político que estava sendo realizado (SAPRIZA, 2015).

Muitos delas institucionalizadas, outras não. A discussão ganha mais intensidade com a chegada da Frente Ampla (esquerda) ao poder em 2005. Embora o então presidente progressista não apoiasse a pauta, anos mais tarde a mobilização e a permanente discussão possibilitada permitiu com que o presidente Pepe Mujica conseguisse sua aprovação em 2012.

A compreensão do caso uruguaio e do desenvolvimento do movimento de mulheres no interior desse país leva a uma primeira noção de como tem operado o feminismo latinoamericano desde a sua gênese até os dias de hoje. Os coletivos que nesse estudo foram situados inicialmente no plano conceitual precisam ser situados também em um panorama histórico-social.

No caso chileno, os progressos ou refluxos do feminismo servem para mostrar que as aparições do movimento de mulheres na história do país são muito mais determinadas pela estrutura de oportunidades do momento e da articulação esporádicas das ativistas em torno da questão do que por uma suposta espontaneidade advinda do processo de desenvolvimento dos fatos (MORA e RIOS, 2009).

Quando as venezuelanas Claudia Mora e Marcela Rios se referem ao movimento de mulheres chileno, partem de uma concepção de movimentos sociais bastante particular: a de que eles se constituem enquanto um grupo dotado de solidariedade grupal e de um objetivo comum para plantear desafios coletivos (MORA e RIOS, 2009).

A argumentação de que mobilizações em torno de determinados temas são propiciadas por contextos políticos favoráveis tem raízes na Teoria do Processo Político de Tilly e Arrow, dois autores que se insurgiram contra o esgotamento da teoria marxista e suas possibilidades interpretativas (ALONSO, 
Coletivos: um balanço da literatura sobre as novas formas de mobilização da sociedade civil

2009). Partindo da ideia de que existem Estrutura de Oportunidades Políticas (EOP) que aparecem eventualmente com a modificação dos ambientes político-institucionais dando espaço para que grupos fora da polity se manifestem, Claudia Mora e Marcela Rios ao analisarem o Chile conseguem observar momentos em que o panorama político esteve mais permeável a discussões sobre gênero e outros nos quais qualquer debate nesse sentido ficou oculto.

Assim como aconteceu no Uruguai, o primeiro grande êxito do movimento de mulheres na história chilena foi a conquista do direito ao voto no ano de 1949. Direito esse que foi exercido pela primeira vez no ano de 1952. Após esse breve intervalo de tempo no qual se acumularam as expectativas participativas, o feminismo passa a viver um período de silêncio na sociedade chilena, que perpassa as décadas de 1950 e 1960 (MORA e RIOS, 2009). O "silêncio feminista", como as autoras ressaltaram em sua análise, só veio a ser quebrado curiosamente no período da ditadura militar de Pinochet, por volta de meados da década de 1970.

Tal qual no Uruguai, a noção de que havia uma igualdade e estabilidade entre homens e mulheres acabou habitando o imaginário social dos chilenos nas décadas de 50 e 60, enquanto a ditadura forçou uma reorganização das feministas na luta pela democracia e um alinhamento das forças progressistas para derrubar o ditador de então. Foi em virtude desse cenário controverso que as mulheres voltaram a "ecoar" a sua voz na esfera pública nacional, mesmo com todas as limitações impostas.

Com a redemocratização do país, se instituiu então o feminismo pós-ditadura. Apesar da diversidade de correntes existentes, a tentativa do movimento foi a de promoção de uma política de coalizão (MORA, RIOS, 2009). Essa política teve como pilar central a tentativa de construção de uma identidade comum entre as mulheres chilenas, visando o fechamento de 
posição comum em torno de algumas pautas de gênero específicas (MORA e RIOS, 2009).

A articulação de identidades femininas diversas serviu como uma estratégia pertinente para fazer frente à quadros político-sociais nos quais a EOP não se manifestasse de maneira tão favorável. Em meados dos anos 2000, o movimento feminista recebe um grande impulso com a campanha e posterior eleição de Michelle Bachelet, candidata do Partido Socialista.

Bachelet trouxe como mote da campanha a problemática da "igualdade de gênero" como algo que precisa ser alcançado. Pela primeira vez na história política do Chile não só é explicitada a campanha de uma mulher para presidência, mas também o fato de que um programa de políticas públicas favoráveis para as mulheres esteve sendo apresentado (MORA e RIOS, 2009).

O feminismo enquanto movimento dotado do binômio discurso-ação (SAPRIZA, 2015) se organizou no pós-ditadura chileno com base em uma rejeição às estruturas institucionais vigentes, pois devido à multiplicidade de demandas dos mais variados segmentos, pressupunha um questionamento da ordem econômica-social (MORA e RIOS, 2009).

Essa não-institucionalidade do movimento o aproxima do que autores como Rebecca L. Bordt(1990) entendem por coletivo, embora seja preciso considerar a dimensão de fluidez dos movimentos que esses autores abordam em comparação com o movimento feminista chileno que caminhou historicamente em direção ao Estado ao culminar com a eleição de Michelle Bachelet e que também se articulou na produção de questionamentos e preenchimentos da agenda pública de toda ordem.

Um exemplo claro disso é a entrada de muitas discussões referentes a gênero, tal qual o problema da violência contra a mulher e os direitos à saúde reprodutiva (MORA, 
Coletivos: um balanço da literatura sobre as novas formas de mobilização da sociedade civil

RIOS, 2009) no contexto político pós-Bachelet. Embora a legalização do aborto não tenha sido aprovada como no Uruguai e o Chile tenha a legislação mais restritiva da América do Sul no que diz respeito a esse quesito, a discussão chegou ao centro do Parlamento, muito em razão da confluência entre o ambiente político e as ações históricas do movimento feminista no país.

Dentre os avanços ocorridos através do florescimento da Estrutura de Oportunidades Políticas (EOP) durante a administração Bachelet estiveram a distribuição de anticoncepcionais para emergência e a ampliação da rede de cuidados infantis aos mais pobres (MORA e RIOS, 2009). O estudo das venezuelanas que está ancorado sobre a teoria norte-americana do processo político elaborada a partir da visão de Tilly e Tarrow indicam que o contexto e as possibilidades positivas ou negativas trazidas pela mudança do controle no Estado foram decisivas para a mobilização dos movimentos feministas não institucionais no país.

Segundo essa teoria, coletivos ou quaisquer outros tipos de movimentos no Brasil e em outros países da região e do mundo tem seu surgimento facilitado dependendo do governo que se sedimenta no momento. Governos de esquerda tenderão, se pelo menos a não apoiar medidas específicas na direção, mas pelo menos em tornar mais flexíveis os espaços para debate e discussão de determinados pontos, como foi no caso do Chile, já que a problematização em torno da questão de gênero é um tema cujas posições mais favoráveis advém de correntes políticas progressistas.

Em relação aos artigos norte-americanos e indianos, importante contribuição foi dadapor Rebecca L.Bordt (1990), pesquisadora sobre gênero da Universidade Depauw. Seu artigo escrito no final da década de 1980 é uma baliza para essa análise e para outras análises que possam vir a ser feitas a respeito de coletivos em outras ocasiões, pois parte de uma 
noção inicial de que existem duas esferas bem distintas de organização: a institucional e a coletivista.

No caso, Bordt (1990) se baseia não em uma ou outra teoria dos movimentos sociais que ajude a explicar melhor o tipo de organização que está sendo estudada, mas sim busca, apesar da sua experiência no campo da sociologia, um caminho analítico na teoria neoinstitucionalista tão recorrente entre os cientistas políticos.

Já Anne M.Valk, historiadora da Universidade de Brown nos EUA, fez um trabalho de resgate dos elementos essenciais para a formação dos coletivos lésbicos na sociedade estadunidense no final da década de 1960. A auto-organização de mulheres lésbicas em coletivos se dá a partir de um questionamento central dos preceitos fundamentais da sociedade patriarcal e do próprio feminismo em voga. $\mathrm{O}$ dissenso das que se autointitulavam lésbicas com relação às outras mulheres feministas ocorre na cidade de Washington na passagem para os anos 1970 (VALK, 2002).

O motivo da ruptura se deu devido ao fato desse grupo minoritário ter discordado das práticas hegemônicas do feminismo já que grupos considerados detentores de uma espécie de "poder dominante", ou seja, homens e mulheres heterossexuais, tomaram a frente do movimento historicamente. O coletivo em questão ficou conhecido com o nome de The Furiese inicialmente propunha uma concepção na qual um pequeno número de mulheres brancas lésbicas se organizasse com o propósito de discutir temáticas relevantes (VALK, 2002).

Numa etapa posterior, esse coletivo passaria a funcionar como uma "federação dos estados feministas", convocando mulheres de todo o país e das mais diversas matizes para participar do processos de construção do movimento, bem como homens eventualmente, facilitando assim que mudanças 
Coletivos: um balanço da literatura sobre as novas formas de mobilização da sociedade civil

sociais mais bruscas pudessem ocorrer a partir dali (VALK, 2002).

A estruturação do movimento estava baseada na gradual modificação das relações interpessoais entre os próprios sujeitos integrantes e no estímulo e produção de atividades reflexivas que fizessem com que os membros adquirissem conhecimento acerca das questões de frente do coletivo. A produção de conhecimento no espaço da mobilização resultou inclusive na criação da própria revista do coletivo, produzida a partir do colaboracionismo horizontal dos componentes (VALK, 2002).

Jornais, oficinas de trabalho etc. foram mecanismos adotados pelo The Furiescomo um dos pioneiros no assuntoe, portanto, provieram um importante legado para o ativismo feminista futuro. Nos anos 1970, década na qual por um breve intervalo ganhou muito destaque, os segmentos feministas que foram se sucedendo na mobilização adotaram muitos desses métodos.

Segundo Anne M.Valk, o coletivo The Furies passou a ser lido por alguns historiadores e observadores como um empecilho para a eficiência e a produtividade do movimento feminista de então, já que ao invés de apostar na união das mulheres em torno de pautas de gênero que fossem úteis ao conjunto do sexo feminino, preferiram adotar uma perspectiva sectária que já havia fracassado em produzir algum tipo de resultado no seio do feminismo radical.

Assim como as feministas radicais, aquelas que integravam o coletivo lésbico The Furies, enfatizaram demasiadamente a conexão entre percepções pessoais e enquadramentos políticos. Isso acabou gerando a noção de que uma nova sociedade seria construída com base nas próprias experiências vividas pelas integrantes, causando um conflito entre $\log o s$ e práxis que teria sido responsável pela própria dissolução do movimento (VALK, 2002). 
Uma das criações educacionais do coletivo, como apontou a pesquisadora, foram as revistas de teoria feminista. Elas propunham nos seus escritos, inicialmente presentes no periódico intitulado Motive e depois no The Furies, elaborações normativas que se opusessem ao mainstream da teoria e alternativas políticas para mulheres radicais militantes.

Durou entre janeiro de 1972 e junho de 1973, sem a publicação de notícias ou outros elementos que não os similares à artigos acadêmicos. A iniciativa foi duramente criticada por outra revista feminista, a Spectre, por não propor uma comunicação política adequada com mulheres de fora o movimento, sugerindo que as experiências de mulheres deveriam ser o melhor intermediador de um diálogo (VALK, 2002).

O que fica claro aqui é não só a maneira pela qual se organiza o coletivo e as ideias que o formaram e o constituem na luta por reconhecimento de um grupo minoritário, mas a própria ideia de como as práticas dos coletivos podem entrar em choque com as pautas, na medida em que o próprio movimento entra em contradição lógica ou o que era proposto inicialmente nada mais é do que uma agenda inexequível. $\mathrm{O}$ princípio da auto-organização fica latente no estudo de Anne M.Valk (2002) assim como nas teorizações de Rebecca L.Bordt(1990).

Auto-organização essa que no caso do coletivo The Furies se dá em um momento de dissenso peculiar das feministas lésbicas. Quando se observa a formulação teórica dos coletivos feministas estudada por Bordt, a questão é outra: seu aparecimento é uma rejeição do próprio movimento às formas burocráticas tradicionais, já que o feminismo a despeito de ser um movimento de emancipação do sujeito feminino, é também uma corrente de pensamento crítica às formas modernas de organização (BORDT, 1990). 
Coletivos: um balanço da literatura sobre as novas formas de mobilização da sociedade civil

No caso dos coletivos de mulheres indianas, o seu surgimento se encontra atrelado à necessidade de instituição de formas organizacionais mais transparentes. Esse fato relevante, além de outros, está presente no estudo de Desouza (2015) intitulado The StrenghtCollective Processes: An "outcomeanalysis" ofwomen'scollectives in India. Nele a autora cita a existência de estruturas hierárquicas dentro do coletivo de mulheres.

Partindo desse princípio, por um ângulo pode se vislumbrar que há uma contraposição da análise representada pela autora pelo que se entende por "coletivo" no Ocidente, particularmente o tipo de movimento que se está querendo compreender. Por outro ângulo, os processos organizativos visíveis na Índia podem apresentar uma ou outra característica a menos do objeto.

A segunda visão se mostra mais plausível quando se faz uma análise detida do que foi encontrado. Os coletivos indianos funcionam através do trabalho voluntário, do estabelecimento de vínculos com a comunidade ao qual estão associados, da colaboração com outros canais de mobilização etc. Os coletivos de mulheres apresentados pelos estudiosos se assemelham a movimentos femininos comunitários de proteção daquelas mulheres que são vítimas das mais diversas formas de opressão e violência.

É importante considerar a descrição que Desouza (2012) faz do que seja a ideologia "coletiva" do movimento, que se assemelha à tentativa de Bordt (1990) de desnudar o princípio do "coletivismo". A ideologia "coletiva" que rege os coletivos de mulheres indianos é composta das seguintes características: a presença de valores centrais que guiam a manutenção da organização; a adoção de uma abordagem holística que propicia o funcionamento coletivo do movimento; inter-relação entre indivíduo e grupo, que permite com que o indivíduo tenha um grau considerável de autonomia dentro da 
mobilização; a agenda de mobilização varia recorrentemente e as funções de rotina tem predominância (DESOUZA, 2015).

A literatura acadêmica brasileira sobre coletivos traz alguns importantes estudos de caso para compreender a realidade do objeto de estudo em questão. Inclui desde coletivos de saúde, passando pelos coletivos de cultura até chegar aos coletivos de gênero. Enquanto o contato com os estudos estrangeiros se deu majoritariamente por meio da temática do reconhecimento da identidade e dos direitos da mulher, a inserção analítica nos textos nacionais permite expor exemplificações as mais diversas.

Duas breves análises que tem como centro coletivos que abordam a temática da saúde foram detectadas. Ambas de autoria de estudiosos da área da psicologia. O primeiro deles consiste no artigo intitulado Participação social e protagonismo em saúde mental: a insurgência de um coletivo de Diogo Faria Corrêa da Costa e Simone MainieriPaulon (2012). Para se observar as sutilezas de um coletivo enquanto movimento social, certamente a produção acadêmica em psicologia irá destoar dos ditames analíticos esperados. Porém, o que é importante destacar é a ilustração feita da modalidade de engajamento que se quer ocorrer (decidida por resolução, mas não aplicada) dentro do espaço de saúde estudado, como uma maneira de construir espaços participativos inovadores.

No caso do pequeno relato feito pela dupla de autores, o coletivo é entendido dentro da instituição psiquiátrica retratada como uma forma de organizar a inserção dos sujeitos integrantes nos espaços de participação possíveis em contraponto à vocalização restrita que se dá nos canais deliberativos formais. $O$ que se quer afirmar é que não necessariamente o exercício da autonomia e do protagonismo daqueles que estão introjetados nos cenários associativos deva se dar de maneira a seguir os mesmos ritos procedimentais anteriormente validados. Logo, por coletivo compreende-se um 
Coletivos: um balanço da literatura sobre as novas formas de mobilização da sociedade civil

plano de existência fértil para maneiras outras de viver a vida (COSTA e PAULON, 2012).

O outro estudo é chamado "Coletivo da música: um estudo sobre relações entre arte e saúde mental". Nele, os psicólogos José Luiz Dias Siqueira e Angela Maria Chagas Villasuso Lago (2012) analisam o Coletivo da música, um coletivo que permite aos usuários da saúde mental a experiência com atividades musicais dentro de um hospital psiquiátrico na cidade de Campinas em São Paulo. O coletivo surgiu em 2009 com a intenção de articular uma série de atividades musicais existentes na Rede de Saúde Mental que se encontravam dispersas (SIQUEIRA e LAGO, 2012).

O coletivo realiza diversas atividades como a apresentação dos pacientes em diversos espaços fora das instituições psiquiátricas, programas de rádio amadores, desfiles carnavalescos etc. (SIQUEIRA e LAGO, 2012). O Coletivo da música é uma organização que funciona por meio da consonância entre profissionais da área e os pacientes. Isso significa que a elaboração das atividades parte daqueles que cuidam dos pacientes, porém a execução é feita unicamente por aqueles que estão se tratando, permitindo com que os mesmos tenham melhorias no quadro e possam se sentir reconhecidos pelos outros ao aprenderem a tocar instrumentos ou cantar músicas (SIQUEIRA e LAGO, 2012).

Os estudos encontrados sobre coletivos de cultura na literatura nacional dizem respeito a dois coletivos: os coletivos de cultura ligados à Bienal da UNE e os coletivos juvenis da cidade de São Paulo que realizam atividades culturais.

Em primeiro lugar, têm-se os coletivos analisados por Marcos Ribeiro Mesquita, estudioso de juventude e participação política da UFAL, que são organizações culturais criadas no final da década de 1990 juntamente com a inauguração da Bienal da UNE. O seu intuito é o de ajudar a promover o evento, reviver os antigos Centros Populares de 
Cultura dos anos 1960 e incluir no movimento estudantil brasileiro formas não institucionais mais adequadas às novas gerações de jovens.

Segundo o autor, movimentos de representação dos estudantes têm ficado cada vez mais esvaziados devido às formas organizacionais tradicionais. $O$ seu grau de institucionalidade fica bastante claro quando do seu esgotamento em obter adesões, tendo em vista a crise recente pela qual vem passando as formas engessadas de representação (MESQUITA, 2008).

Para fazer frente a isso, o modo de conceber entidades como a União Nacional de Estudantes (UNE), pautada sob uma série de regulamentos e pela ligação com legendas políticas de esquerda, tem se metamorfoseado com vistas a trazer um extenso público estudantil que veio se perdendo nas últimas décadas a partir da não atratividade dos eixos estruturais consolidados na organização.

Tal metamorfose se deu a partir da aproximação com os meios artístico e cultural e através da criação de coletivos de cultura que ajudaram a fortalecer o diálogo entre a instituição e seus membros e não membros (MESQUITA, 2008). O estudo de Mesquita aborda o modo pelo qual se dá a relação UNE Coletivos.

Os coletivos se apresentam especialmente na Bienal da UNE que ocorre de dois em dois anos, porém seu funcionamento ocorre normalmente nas mais diversas universidades brasileiras quando do intervalo entre os eventos. Uma das dificuldades tem sido manter esses coletivos em atividades fora dos períodos próximos da Bienal (MESQUITA, 2008). O autor não se preocupa com teorizar acerca dos coletivos, apenas em dar o exemplo de um tipo e mostrar como tem se dado seus trabalhos.

Essa preocupação também não é a de Silvia Helena Simões Borelli e Ariane Aboboreira, ambas da PUC-SP. 
Coletivos: um balanço da literatura sobre as novas formas de mobilização da sociedade civil

Embora discorram sobre a importância de considerar as narrativas dos sujeitos participantes dos coletivos como espécies de "lugares metodológicos" e como se dão os procedimentos de seleção e análise dos coletivos juvenis na cidade de São Paulo, as explanações teóricas sobre os movimentos sociais não são objeto de abordagem (BORELLI e ABOBOREIRA, 2011).

No mais, as autoras mostram que esses coletivos juvenis são movimentos de cultura localizados em diferentes bairros da cidade de São Paulo e possuem ampla ligação com a Secretaria de Cultura do Estado em São Paulo, pois a mesma possui uma série de programas e possibilidades de financiamento voltados para projetos de cultura locais. Aqui fica evidente a relação entre mobilização social e estado, também apontada pela literatura sobre sociedade civil e movimentos sociais (ABERS e VON BÜLOW, 2011; LAVALLE e SWAKO, 2015).

No grupo dos estudos acadêmicos nacionais sobre coletivos, foi encontrado apenas um estudo sobre coletivos de gênero. Realizado por Glauco Ferreira da Universidade Federal de Santa Catarina o artigo Margeando Ativismos Globalizados: o caso do Mujeres Al Borde trata do Mujeres Al Borde, um coletivo artístico colombiano que articula as relações entre arte, ativismo e produção audiovisual (FERREIRA, 2015).

O movimento aborda questões étnico-racionais, de gênero e sexualidade e tem como objetivo não só a divulgação dessas pautas centrais, fomentando o ativismo Queer no Sul e no Norte globais, mas também a construção de amplo conteúdo a ser veiculado relacionado aos temas centrais do coletivo.

Criam-se outras possibilidades de interação com os sujeitos de fora do coletivo, na medida em que existem chances de trazer aquilo que foi moldado culturalmente para o âmbito das diversas formas de mídia, impressa e eletrônica, capazes de potencializar demandas e reivindicações identitárias no cerne 
de uma sociedade eminentemente conservadora como a colombiana.

Essa construção se dá não de forma endógena, mas em parceria com produtoras de vídeo estrangeiras que também se comprometem a criar material de denúncia às violências sofridas por inúmeros grupos, mas principalmente pela população LGBT, na esfera pública e de maneira geral, já que as opressões a certos sujeitos têm origem na própria natureza dos controles instituídos.

\section{Conclusões}

Com base no que foi descrito pode-se afirmar consistentemente que os coletivos enquanto novas formas de mobilização da sociedade civil ainda carecem de estudos no âmbito da literatura sobre movimentos sociais, tanto na nacional quanto nas estrangeiras que foram inseridas no recorte dessa pesquisa. Os caminhos analíticos, principalmente no que se refere à esfera teórica, possuem largos espaços para serem explorados em futuras pesquisas que abordem a tema, tendo em vista a baixa sistematização ou mesmo a ausência de conceituações de coletivos.

No concernente à esfera empírica, alguns estudos e observações já tem sido feitas nos três grandes grupos de artigos detectados e utilizados na pesquisa, indicando uma abertura para estudos de caso comparados sobre essa nova modalidade de engajamento.

Os artigos analisados trouxeram apontamentos fundamentais para compreender a maneira como estão caracterizados e como atuam os movimentos autodenominados coletivos. Dentre os elementos mencionados no decorrer do artigo e que consistem em pontos centrais dessas formas de mobilização estão: a horizontalidade, a não institucionalidade, a 
Coletivos: um balanço da literatura sobre as novas formas de mobilização da sociedade civil

auto-organização e a temporalidade. Esses elementos não necessariamente devem ser detectados juntos num mesmo coletivo, mas podem aparecer esparsos ou em maior ou menor grau. Um exemplo disso tem sido a questão da institucionalidade nos coletivos analisados. Alguns deles, embora existam enquanto formas não institucionais, acabam por se ligar ao Estado como é o caso dos coletivos feministas analisados por Bordt (1990) ou os de juvenis e de cultura analisados por Borelli e Aboboreira (2011), que tem uma relação intrínseca com a Secretaria de Cultura do Estado de SP; ou então se ligam a entidades já bastante institucionalizadas, como é o caso dos coletivos de cultura formados com vistas à participação na Bienal da UNE.

Depreende-se daí que institucionalidade ou não institucionalidade, verticalidade ou horizontalidade, entre outras linhas de conflitualidade, são essenciais para que comece a se observar os coletivos não apenas como agregações de sujeitos em torno de pautas comuns, fixas e rígidas; mas sim enquanto associações fluidas de corpos diferentes em prol da objetivação de mudanças culturais ou até mesmo simbólicas no meio social no qual se encontram inseridos. Tratando de cultura, gênero ou quaisquer outras questões de relevância em espaços intra ou extra acadêmicos, tais formas de engajamento tem conquistado adeptos, principalmente no que se liga à problemas de afirmação identitária e reconhecimento.

$\mathrm{Na}$ transição do que alguns autores chamam de modernidade para a pós-modernidade, na qual os sujeitos da contemporaneidade estariam inseridos, não é só a crise das "grandes narrativas" ou um pretenso e controverso "fim da história" que dominam a cena. O surgimento de novos meios de luta e comportamentos de contestação peculiares tem pautado a tônica do que hoje é a discussão sobre os novos ou mesmo os novíssimos movimentos sociais. 
Os coletivos se inserem nesse panorama recente, no qual a liquidez relacional e a experimentação de novas formas de ser tem se estruturado cada vez mais a caminho de um tipo de sociedade em que o verbo "contestar" seja a marca presente nas mais variadas esferas, públicas e privadas. Quem sabe assim, novas formas de mobilização deem origem a novos tipos de institucionalidade e abram espaços para outros campos de diálogo.

\section{Referências bibliográficas}

ABERS, Rebecca; VON BÜLOW, Marisa. Movimentos sociais na teoria e na prática: como estudar o ativismo através da fronteira entre Estado e sociedade? Sociologias, ano 13, n. 28, 2011. p.5284.

ALEXANDER, Jeffrey C. Ação coletiva, cultura e sociedade civil: Secularização, atualização, revisão, inversão e deslocamento do modelo clássico de movimentos sociais. Revista Brasileira de Ciências Sociais. vol.13. n.37. São Paulo. Junho 1997.

ALONSO, Ângela. As teorias dos movimentos sociais: um balanço do debate. Lua Nova, São Paulo, 76: 49 - 86, 2009.

AMADOR, Arthur Calheiros; CASTRO, Eliane Dias de. O Coletivo (com preguiça): encontros, fluxos, pausas, artes. Interface, 2016; 20(56): 267 - 280.

AVRITZER, Leonardo.Sociedade civil e Estado no Brasil: da autonomia à interdependência política. OpiniãoPública. Vol. 18. No.2. Campinas. Novembro 2012

BORDT, Rebecca L. How alternative ideas become institutions: the case of feminist collectives. Nonprofit and Voluntary Sector Quarterly, vol.26, no.2, June 1990. 132 - 155

BORELLI, Silvia. ABOBOREIRA, Aline. Teorias/metodologias: trajetos de investigação com Coletivos junis em São 
Coletivos: um balanço da literatura sobre as novas formas de mobilização da sociedade civil

Paulo/Brasil. Revista Latinoamericana de CienciasSociales, Niñez y Juventud, 1 (9), 2011. p. 161 - 172.

COSTA, Diogo Faria Côrrea da; PAULON, Simone Mainieri. Participação social e protagonismo em saúde mental: a insurgência de um coletivo. Saúde em debate - Rio de Janeiro, v.36, n.95, p.572 - 582, out/dez. 2012.

DESOUZA, Shaila. The Strenght of Collective Processes: An "Outcome Analysis" of Women's Collectives in India. IndianJournalofGenderStudies. 19 (3). 373 - 392

FERREIRA, Glauco. Margeando ativismos globalizados: nas bordas do Mujeres Al Borde. Estudos Feministas, Florianópolis, 23(1): 312, janeiro-abril/2015

GOHN, Maria da Glória. Movimentos sociais na contemporaneidade. Revista Brasileira de Educação v. 16 n. 47 maio-ago. 2011

HABERMAS, Jürgen. Theorie des KommunikativenHandels. Band I. Handlungsrationalität und geselchaftlicheRationalisierung. FrankfutamMain: Suhrkamp, 1981.

HOBSBAWM Eric J. A Era dos Extremos: o breve século XX: 1914-1991 - São Paulo: Companhia de Letras, 1995.

LAVALLE, A. G. e SWAKO, J. 2015. Sociedade civil, Estado e autonomia: argumentos, contra-argumentos e avanços no debate. Opinião Pública, Campinas, vol. 21, no 1, abril, p. 157187.

MAIA, Gretha Leite. A juventude e os coletivos: como se articulam novas formas de expressão política. Revista Eletrônica do Curso de Direito da UFSM. v.8, n.1/2013.

McADAM, Doug; TARROW, Sidney e TILLY, Charles. Para Mapear o Confronto Político. Lua Nova, São Paulo, 76: 11-48, 2009.

MELUCCI, Alberto. Um objetivo para os movimentos sociais? Revista Lua Nova. São Paulo. Junho 1989. № 17 
MESQUITA, Marcos Ribeiro. Cultura e política: a experiência dos coletivos de cultura no movimento estudantil. Revista Crítica de Ciências Sociais, 81, Junho 2008: 179 - 207.

MORA, Claudia; RIOS, Marcela. De Política de Representación a Política de Coalición? Posibilidades de Movilización Feminista em el Chile Post-Dictadura. Polis, Revista de laUniversidad Bolivariana, Volumen 8, № 24, 2009, p. 133-145.

PEREIRA, André. Movimentos sociais: conceituações e materializações. CIES e-WorkingPaper. № 163/2013.

RIBEIRO, Fernando. Institucionalismo da escolha racional e institucionalismo histórico: divergências metodológicas no campo da Ciência Política. Pensamento Plural. Pelotas (10): 89 100 janeiro - junho 2012.

SAPRIEZA, Gabriela. "Nos habíamos amado tanto". Añosrevueltos. Mujeres, colectivos y lapelea por elespacio público. Estudos feministas, Florianópolis, 23 (3): 406, setembro-dezembro/2015.

SAMPAIO, R.F.; MANCINI, M.C.. Estudos de revisão sistemática: um guia para síntese criteriosa da evidência científica. Rev. bras. fisioter., São Carlos , v. 11, n. 1, p. 83-89, Fev. 2007. Disponível em $<$ http://www.scielo.br/scielo.php?script=sci_arttext\&pid=S141335552007000100013\&lng=en\&nrm=iso $>$. Acesso em 21 de outubro de 2016.

TARROW, Sidney. O poder em movimento: movimentos sociais e confronto político. Petrópolis: Vozes, 2009.

TILLY, Charles. Os movimentos sociais como política. In Revista Brasileira de Ciência Política, no.3, Brasília, janeirojulho, 2010, p.133-160.

TOURAINE, Alan. Os novos conflitos sociais: para evitar mal entendidos. RevistaLua Nova. São Paulo. Junho 1989. № 17.

VALK, Anne M. Living a Feminist Lifestyle: The Intersection of Theory and Action in a Lesbian Feminist Collective. Feminist 
Coletivos: um balanço da literatura sobre as novas formas de mobilização da sociedade civil

Studies, vol.28, no.2, Second Wave Feminism in the United States (Summer, 2002), pp.303 - 332.

Enviado: 21/12/2016

Aceito: 19/04/2017 